\title{
Avaliação do tratamento com isoniazida em bovinos infectados naturalmente pelo Mycobacterium bovis
}

[Evaluation of the treatment with isoniazid carried out in bovines naturally infected with Mycobacterium bovis]

\author{
P.M.P.C. $\mathrm{Mota}^{1}$, P.M.C. $\mathrm{Motta}^{3}$, F.C.F. Lobato $^{2}$, A.P. Lage $^{2}$, A.C.C.L. Ribeiro ${ }^{4}$, R.C. Leite $^{2}$ \\ ${ }^{1}$ Laboratório Regional de Apoio Animal - LARA-MG \\ Av. Rômulo Joviano, S/N \\ 33600-000 - Pedro Leopoldo, MG \\ ${ }^{2}$ Escola de Veterinária - UFMG \\ ${ }^{3}$ Aluno de graduação da Escola de Veterinária - UFMG \\ ${ }^{4}$ EMBRAPA Gado de Leite - Coronel Pacheco, MG
}

\section{RESUMO}

Foi adotado o tratamento intermitente da tuberculose com isoniazida em 240 bovinos de um rebanho naturalmente infectado pelo $M$. bovis. No início do tratamento $36,6 \%$ dos animais foram reagentes positivos e $2,9 \%$ inconclusivos. Todos os animais do rebanho receberam isoniazida por via oral em doses de $25 \mathrm{mg} / \mathrm{kg}$ de peso vivo, administrada três vezes por semana, às segundas, quartas e sextas-feiras, durante 10 meses, perfazendo 120 doses. A cura de 98,9\% dos animais tratados foi verificada por meio da dessensibilização alérgica realizada pela tuberculinização e controle bacteriológico de 39 animais abatidos. O tratamento neste rebanho não resultou em seleção de cepas resistentes a isoniazida, comprovada pelo teste de sensibilidade a essa droga, realizado em cultura de $M$. bovis isolada de um animal não curado.

Palavras-chave: bovino, tuberculose, tratamento intermitente, isoniazida

\section{ABSTRACT}

The intermittent treatment with isoniazid was adopted in 240 bovines from a naturally infected herd. At the beginning of the treatment, $36.6 \%$ of the animals were positive reactors and $2.9 \%$ inconclusive reactors. The drug was administered orally at a dose of $25 \mathrm{mg} / \mathrm{kg}$ of live weight, three times a week (on Mondays, Wednesdays and Fridays) during 10 months in a total of 120 doses. The cure of $98.9 \%$ of the treated animals was verified by the allergic desensitization demonstrated through the tuberculin test and the bacteriological control of 39 slaughtered animals. The treatment in this herd did not cause selection of isoniazid-resistant strains as demonstrated by the isoniazid sensitivity test carried out in M. bovis culture isolated from a non-cured animal.

Keywords: bovine, tuberculosis, intermittent treatment, isoniazid

\section{INTRODUÇÃO}

Várias drogas foram testadas no tratamento da tuberculose, sem sucesso. Em 1944, Waksman, pela primeira vez, empregou a estreptomicina no tratamento da tuberculose. Posteriormente, novas drogas foram incorporadas ao arsenal terapêutico da tuberculose. Em 1946 o ácido-para-aminosalicílico, em 1952 a isoniazida e em 1957 a rifampicina. Atualmente, das 16 drogas conhecidas com ação efetiva sobre o bacilo da tuberculose, seis são de uso preferencial no

Recebido para publicação em 31 de julho de 2003

Recebido para publicação, após modificações, em 31 de agosto de 2004

E-mail:pmcmotta@yahoo.com.br 
tratamento da tuberculose humana: estreptomicina, rifampicina, etambutol, pirazinamida, etionamida e isoniazida. Resultados aparentemente favoráveis levaram vários pesquisadores, em diversos países, a realizarem estudos sobre a eficácia da isoniazida no tratamento curativo e profilático da tuberculose bovina.

Para minimizar os prejuízos dos proprietários de rebanhos com tuberculose, vários tratamentos foram propostos utilizando-se isoniazida com posologia variada. Moretti e Pedini (1952) foram os primeiros a relatar ensaios sobre o tratamento da tuberculose bovina com isoniazida. Kleeberg (1967), na África do Sul, e Langenegger et al. (1991b), no Brasil, ampliaram os estudos sobre posologia e tempo de tratamento, obtendo bons resultados principalmente quando se utilizou o tratamento intermitente, com altas dosagens de isoniazida por períodos prolongados.

A isoniazida, hidrazida do ácido isonicotínico, altamente solúvel em água, é facilmente absorvida no trato digestivo e não interfere com a microbiota local. Sofre rápida difusão em todos os líquidos e células do organismo, atingindo níveis terapêuticos que perduram por 18-24 horas no soro, nos tecidos e nas lesões tuberculosas. É metabolizada principalmente no fígado por acetilação e excretada, essencialmente, via renal (Kleeberg, 1967). A isoniazida é bacteriostática para o bacilo em repouso e bactericida para microrganismos em rápida divisão, mas somente as micobactérias do complexo M. tuberculosis são susceptíveis à sua ação (Shinnick, 1996). Ela inibe a biosíntese do ácido micólico presente na parede das micobactérias do complexo $M$. tuberculosis, levando a perda da ácidoresistência. Quando de sua ação mais prolongada, a droga pode afetar a síntese de proteína e ácidos nucléicos da bactéria (Shinnick, 1996).

O tratamento da tuberculose bovina, principalmente nas bacias leiteiras de Minas Gerais e São Paulo, tornou-se rotina em rebanhos infectados com M. bovis. Em alguns casos, por falha no diagnóstico, está sendo aplicado de maneira incorreta em rebanhos portadores de reações inespecíficas. A rotina do tratamento da tuberculose bovina tornou-se tão comum que algumas cooperativas, vendem isoniazida em grande quantidade sem nenhum controle.
Em razão do uso indiscriminado do tratamento com isoniazida em bovinos, esta pesquisa teve o objetivo de avaliar a quimioprofilaxia e o tratamento por meio de cura bacteriologia e dessensibilização alérgica.

\section{MATERIAL E MÉTODOS}

Foram utilizados 240 bovinos mestiços holandêszebu, quatro reprodutores, 119 vacas, 60 novilhas e 57 bezerros, criados em uma propriedade especializada na produção de leite, localizada na Zona da Mata do Estado de Minas Gerais. Durante o experimento os animais, mantidos em regime de semi-estabulação, receberam capim e/ou cana triturados e foram suplementadas com ração e dejetos de suínos.

O diagnóstico da tuberculose baseou-se na prova alérgica, no diagnóstico clínico, na necrópsia e nos exames bacteriológicos. $\mathrm{O}$ diagnóstico alérgico foi feito por meio da tuberculinização comparada, empregando-se as tuberculinas PPD bovina contendo $1 \mathrm{mg}$ de proteína por $\mathrm{ml}$ (32500UI) e PPD aviário contendo $0,5 \mathrm{mg}$ de proteína por $\mathrm{ml}$ (25.000UI), produzidas no Laboratório Regional de Apoio Animal em Pedro Leopoldo - Minas Gerais (LARA/MG). As inoculações foram feitas por via intradérmica na dosagem de $0,1 \mathrm{ml}$ na região da escápula, utilizando-se seringa com dosador automático ${ }^{1}$, e a 15 a $20 \mathrm{~cm}$ de distância uma da outra. As tuberculinas aviária e bovina foram inoculadas, respectivamente, nas posições cranial e caudal em relação à espinha da escápula. Os locais de inoculação foram demarcados por depilação de uma área de aproximadamente $4 \mathrm{~cm}^{2}$, utilizandose lâmina de barbear.

As medidas de espessura da dobra da pele, antes da tuberculinização e 72 horas após, foram feitas com cutímetro ${ }^{2}$ equipado com mola. A interpretação das reações foi feita seguindo o critério proposto por Langenegger et al. (1981a).

Antes do início do tratamento, foram realizadas duas tuberculinizações intercaladas de 90 dias em todos animais do rebanho. Para a identificação de possíveis animais anérgicos, foi

\footnotetext{
${ }^{1}$ McLintock. Astra, C.J. Hewlett \& Som Ltda, Watford,

Hents, Inglaterra.

${ }^{2}$ H. Hauptner, Solinger, Alemanha.
} 
realizado exame clínico em todos os animais após o diagnóstico alérgico. Os animais que apresentaram sinais clínicos da doença foram abatidos e submetidos a exame pós-mortem para confirmação bacteriológica da tuberculose.

Devido à impossibilidade de isolamento adequado entre animais reagentes e não reagentes optou-se pelo tratamento profilático dos animais considerados negativos. A isoniazida, sob a forma de sal cristalino, foi fornecida individualmente por via oral, misturada no concentrado. A dose foi de aproximadamente $25 \mathrm{mg} / \mathrm{kg}$ de peso vivo, administrada três vezes por semana, às segundas, quartas e sextas-feiras, durante 10 meses, perfazendo um total de 120 doses. Para facilitar a dosificação, os animais foram pesados e agrupados em lotes com variação de peso corporal de $40 \mathrm{~kg}$, de maneira que todos os animais de cada lote recebessem a mesma quantidade de isoniazida, que variou de 23 a $26 \mathrm{mg} / \mathrm{kg}$ de peso vivo. Os animais até seis meses de idade receberam o medicamento adicionado ao leite. A pesagem foi mensal para correção da posologia. Durante o período de aplicação da medicação não foram feitos testes alérgicos.

A avaliação do tratamento foi feita pela dessensibilização alérgica, inspeção após abate e cura bacteriológica. Também foi pesquisado o possível surgimento de amostras de M. bovis resistentes à isoniazida.

A verificação da dessensibilização alérgica teve início com a primeira tuberculinização, feita 90 dias após o término da medicação. Inicialmente os testes foram trimestrais e, posteriormente, semestral, a partir do sétimo teste, durante aproximadamente cinco anos. Dos 95 animais reagentes antes do início do tratamento, 85 foram abatidos a fím de se observar a presença de alterações patológicas associadas à tuberculose.
Trinta e nove animais foram selecionados após o término do tratamento para controle bacteriológico. Todos foram submetidos a rigorosa inspeção, principalmente dos linfonodos, pulmões, fígado, baço e úbere. De cada animal coletou-se o maior número possível de linfonodos e de fragmentos de órgãos com alguma alteração macroscópica. $\mathrm{O}$ material foi acondicionado em sacos plásticos, transportado em gelo até o laboratório e conservado à temperatura de $-20^{\circ} \mathrm{C}$ até a hora do exame.

De cada amostra foi retirado o tecido conjuntivo adjacente, o qual foi seccionado em fatias de dois a três $\mathrm{mm}$ de espessura sempre utilizando-se instrumental recém-esterilizado. Das amostras com lesões, retiravam-se aproximadamente, 10 gramas de material constituído da parte alterada e pequena quantidade de tecido normal. Dos linfonodos, aparentemente normais, retiravam-se cinco fragmentos de aproximadamente duas gramas. O material era então triturado em gral contendo areia estéril.

A descontaminação foi realizada de acordo com Mota (1985) utilizando solução de ácido sulfúrico a $6 \%$ na proporção de uma parte do material para seis partes de solução de ácido, durante 30 minutos, incluindo 15 minutos de centrifugação a $500 \mathrm{~g}$. O sedimento foi lavado duas vezes com salina e depois semeado em dois tubos contendo meio de Stonebrink. As culturas foram incubadas em estufa bacteriológica à $37^{\circ} \mathrm{C}$ durante dois meses.

Para a avaliação da sensibilidade à isoniazida de amostras isoladas, empregou-se o método das proporções descrito pelo por Kantor (1988).

\section{RESULTADOS E DISCUSSÃO}

O resultado do teste alérgico dos animais tuberculinizados é apresentado na Tab. 1 .

Tabela 1. Resultado da prova alérgica comparada para diagnóstico de tuberculose bovina por categoria animal em um rebanho leiteiro no início do tratamento em novembro de 1997

\begin{tabular}{lcccccc}
\hline Categoria animal & N. $^{\circ}$ de bovinos & N. $^{\circ}$ de negativos N. & de reações inconclusivas & $\%$ & N. $^{\circ}$ de reações positivas & $\%$ \\
\hline Reprodutor & 4 & 4 & 0 & 0 & 0 & 0 \\
Vaca & 119 & 58 & 5 & 4.2 & 56 & 47,0 \\
Novilha & 60 & 44 & 2 & 3.3 & 14 & 23,3 \\
Bezerra & 57 & 39 & 0 & 0 & 18 & 31,6 \\
Total & 240 & 145 & 7 & 29 & 88 & 36,6 \\
\hline
\end{tabular}


Observou-se alta prevalência de animais reagentes positivos entre as vacas, fato característico de rebanhos confinados e altamente infectados, aspecto já citado por Langenegger et al. (1981b).

As pesquisas envolvendo o tratamento da tuberculose com isoniazida em bovinos apresentam três aspectos coincidentes: tempo prolongado de administração da droga, utilização de altas doses e administração intermitente do medicamento.

Devido à impossibilidade de isolamento dos animais reagentes e não reagentes, optou-se pelo tratamento profilático com isoniazida dos animais não reagentes considerados negativos. Embora alguns autores (Moretti e Pedini, 1953; Seelemann e Buschkiel, 1957; Castellani et al., 1959; Spryszak, 1961; Kleeberg, 1967) considerem que doses menores de isoniazida $(10 \mathrm{mg} / \mathrm{kg}$ peso vivo) utilizadas profilaticamente sejam eficientes para impedir a infecção pelo $M$. bovis em animais sadios, nesta pesquisa foram utilizados $25 \mathrm{mg} / \mathrm{kg}$ de peso vivo, isto é, a mesma dosagem usada para os animais reagentes por não se ter certeza de que todos os não reagentes eram efetivamente não infectados ou doentes. Essa dosagem foi utilizada para padronização de pesagem da droga, o que facilitou o manejo na propriedade. A decisão de uniformizar dosagens para animais reagentes e não reagentes não onerou significativamente o custo do tratamento uma vez que o preço da isoniazida significou, aproximadamente, $4 \%$ do valor comercial do indivíduo tratado.

No total foram administradas 120 doses durante 10 meses, tempo significativamente maior do que os 6,5 meses (80 doses) recomendados por Langenegger et al. (1991b). Isso se justificou pela dificuldade em identificar todos os animais portadores de lesões maiores que seriam descartados. Segundo Kleeberg (1967), a cura não é completa com períodos menores de tratamento.

$\mathrm{Na}$ primeira semana do tratamento foram observados sintomas nervosos em bezerras com idades entre 10 e 12 meses. Após revisão, constatou-se que elas estavam recebendo dosagem de isoniazida maior do que a recomendada. Os sintomas terminaram após a suspensão do tratamento por uma semana. Após a correção da dosagem do medicamento, não se observaram alterações no estado geral dos animais até o final do tratamento.

Não houve rejeição ao medicamento misturado à ração concentrada conforme relatou Langenegger et al. (1991b), provavelmente em razão de se administrar a droga com o primeiro arraçoamento do dia, quando os animais estavam mais ávidos pelo alimento.

O resultado do teste alérgico, 90 dias após o término do tratamento, é apresentado na Tab. 2.

Tabela 2. Número e porcentagem de animais dessensibilizados, reagentes suspeitos e positivos e intensidade de reação alérgica, segundo o número de dias após o término do tratamento

\begin{tabular}{|c|c|c|c|c|c|c|c|}
\hline \multirow{3}{*}{ Número de dias } & \multicolumn{2}{|c|}{ Animais negativos } & \multicolumn{4}{|c|}{ Animais reagentes } & \multirow{3}{*}{$\begin{array}{l}\text { AEDP médio dos animais } \\
\text { reagentes }(\mathrm{mm})\end{array}$} \\
\hline & \multirow{2}{*}{ N. ${ }^{o}$} & \multirow{2}{*}{$\%$} & \multicolumn{2}{|c|}{ Suspeitos } & \multicolumn{2}{|c|}{ Positivos } & \\
\hline & & & N. ${ }^{\circ}$ & $\%$ & N. ${ }^{\circ}$ & $\%$ & \\
\hline $0^{*}$ & 145 & 60,4 & 7 & 2,9 & 88 & 36,6 & 9,6 \\
\hline $90 * *$ & 224 & 89,2 & 20 & 7,9 & 7 & 2,7 & 3,5 \\
\hline 180 & 250 & 96,1 & 8 & 3,0 & 2 & 0,7 & 3,1 \\
\hline 270 & 259 & 96,2 & 8 & 2,9 & 2 & 0,7 & 3,0 \\
\hline 369 & 263 & 97,4 & 7 & 2,5 & 0 & 0 & 2,4 \\
\hline 460 & 262 & 87,3 & 20 & 6,6 & 18 & 6,0 & 3,6 \\
\hline 560 & 298 & 96,1 & 10 & 3,2 & 2 & 0,6 & 2,9 \\
\hline 740 & 323 & 97,8 & 7 & 2,1 & 0 & 0 & 2,8 \\
\hline 920 & 330 & 97,0 & 10 & 2,9 & 0 & 0 & 2,4 \\
\hline 1100 & 340 & 99,4 & 2 & 0,5 & 0 & 0 & 2,1 \\
\hline 1310 & 341 & 99,1 & 3 & 0,8 & 0 & 0 & 2,2 \\
\hline 1550 & 331 & 99,0 & 3 & 0,9 & 0 & 0 & 2,2 \\
\hline
\end{tabular}

*Início do tratamento; **Pós-tratamento; AEDP - aumento da espessura da dobra da pele, 
O intervalo de 90 dias entre testes foi recomendado por Avelini e Figorelli (1954) e Kleeberg (1967) como necessário para a eliminação dos resíduos de isonizida e início dos testes. Nos primeiros 560 dias, as tuberculinizações foram realizadas a cada 90 dias e posteriormente a cada 180 dias, durante quatro anos e meio. O primeiro teste revelou que $10,8 \%$ de animais continuavam reagentes, que o aumento médio da espessura da dobra da pele era de $3,5 \mathrm{~mm}$ e que $89,2 \%$ dos animais apresentavam reações menores que $2,0 \mathrm{~mm}$.

Aos 460 dias, após a última dosagem de isoniazida, foi observado aumento repentino do número de reações suspeitas e fracamente positivas com características de reações inespecíficas, principalmente nos animais em lactação. Essas reações foram atribuídas a uma possível infecção por micobactérias atípicas veiculadas pelos dejetos de suínos utilizados na alimentação. Esse aspecto também foi relatado por Langenegger et al. (1976) ao pesquisarem reações inespecíficas em bovinos, as quais diminuíram significativamente de intensidade após a retirada da possível fonte de infecção.

A dessensibilização alérgica ocorreu de forma lenta e gradativa até $\mathrm{o} 11^{\circ}$ teste após o tratamento. Até o sexto teste-controle, aos 560 dias, foram observadas reações acima ou igual ao limiar de positividade $(3,0 \mathrm{~mm})$ para a tuberculina bovina. As reações, em sua maioria, apresentavam pequena intensidade de edema, de consistência endurecida, assemelhando-se a reações inespecíficas. No rebanho observaram-se animais com reações inconclusivas em todos os testes-controle da dessensibilização alérgica. A persistência de sensibilidade alérgica, ou seja, um mesmo animal reagindo em dois ou mais testes consecutivos ocorreu em todas as tuberculinizações. A partir do sétimo teste não foram observados animais com reações positivas.

Aos 1100 dias, após a última dose de isoniazida, a dessensibilização alérgica foi quase completa, com 99,4\% dos animais apresentando reações negativas, índice próximo ao alcançado por Langenegger et al. (1981b; 1991a; 1991b).
Alguns animais não apresentaram dessensibilização completa nos últimos testescontrole. Essa situação, em que a maioria das reações foi maior para a PPD aviária, ou que apenas pequeno número de animais apresentou reações maiores para a PPD bovina, porém ainda na faixa de reações inconclusivas, sem presença de edema, circunscritas e geralmente não observadas no mesmo animal em testes subseqüentes, é atribuída a infecções por micobactérias atípicas. Sua persistência no rebanho provavelmente está relacionada ao uso de forragens adubadas com dejetos de suínos.

A cura de $98,9 \%$ dos animais doentes ou infectados tornou o tratamento econômico, indicando ser uma solução plausível em rebanhos de alto valor zootécnico ou com elevada prevalência.

O saneamento de rebanhos com alta prevalência de tuberculose é uma tarefa difícil quando se utilizam o controle pela tuberculinização e o abate dos animais reagentes. Nesses rebanhos normalmente surgem números significativos de animais reagentes a cada tuberculinização até que sejam descartados todos animais doentes eliminadores de $M$. bovis. Esse problema está relacionado principalmente à sensibilidade do teste alérgico em relação aos animais anérgicos encontrados com freqüência em rebanhos altamente infectados.

No último teste controle, aos 1550 dias após medicação, apenas 10 animais que haviam apresentado reações positivas ou suspeitas no início do tratamento e que ainda eram bezerros na época, permaneceram no rebanho. Os outros 85 animais reagentes e tratados já tinham sido gradualmente descartados. Estes foram abatidos e inspecionados com o objetivo de se detectar a presença de lesões. Desses, sete apresentaram alterações patológicas (Tab. 3), e apenas um (número 21) revelou lesões sugestivas indicando a possibilidade de não ter havido cura.

A Tab. 4 apresenta os valores das reações alérgica dos 39 bovinos abatidos para o estudo bacteriológico. 
Mota et al.

Tabela 3. Alterações anatomopatológicas em bovinos abatidos após tratamento com isoniazida

\begin{tabular}{lccccccccccc}
\hline \multirow{2}{*}{ N. ${ }^{*}$ do animal } & \multicolumn{1}{c}{ Linfonodo/órgão } & \multicolumn{1}{c}{ Tipo de lesão macroscópica } & Isolamento \\
& 1 & 2 & 3 & 4 & 5 & 6 & 7 & 8 & Mycobacterium bovis \\
\hline 10 & + & - & - & + & - & - & - & - & Hemorrágicos & - \\
16 & - & - & - & - & - & + & + & - & Discreta pneumonia & - \\
17 & - & - & + & + & - & - & - & - & Hemorrágicos & - \\
21 & - & + & - & - & - & + & - & + & Calcificados/caseosas & + \\
23 & - & + & - & - & - & - & - & - & Lesão tipo cicatricial & - \\
30 & - & + & - & - & - & + & - & - & Discreta pneumonia & - \\
32 & - & - & - & - & + & - & + & - & Mastite/lesões purulentas & - \\
\hline 1-Linfonodos cervicais, 2-mediastínicos, 3-mesentéricos, 4-pré-escapulares, 5-linfonodos do úbere, 6- pulmões, 7-ubere, 8.-fígado. \\
+ presença de lesões anatomopatológicas; - ausência de lesões anatomopatológicas.
\end{tabular}

Tabela 4. Intensidade das reações alérgicas de bovinos abatidos após tratamento com isoniazida, segundo os meses e anos de abate

\begin{tabular}{|c|c|c|c|c|c|c|c|c|}
\hline \multirow{2}{*}{$\begin{array}{l}\text { Número do } \\
\text { animal }\end{array}$} & \multicolumn{2}{|c|}{$\begin{array}{c}\text { Tuberculinização antes } \\
\text { do tratamento } \\
\end{array}$} & \multicolumn{5}{|c|}{ Tuberculinização após tratamento } & \multirow[t]{2}{*}{ Data do abate } \\
\hline & Ago/97 & Nov/97 & Dez/98 & Mar/99 & Jun/99 & Set/99 & Dez/99 & \\
\hline 1 & 5,2 & - & 2,0 & 1,0 & 0,0 & - & - & Jun/99 \\
\hline 2 & 3,2 & - & 1,0 & - & - & - & - & Dez/98 \\
\hline 3 & 22,4 & - & 5,1 & - & - & - & - & Dez/98 \\
\hline 4 & 25,1 & - & 4,9 & - & - & - & - & Dez/98 \\
\hline 5 & 18,3 & - & 1,6 & 2,2 & 2,7 & - & - & Jun/99 \\
\hline 6 & 17,7 & - & 4,8 & - & - & - & - & Dez/98 \\
\hline 7 & 19,8 & - & 3,4 & 2,3 & 2,8 & - & - & Jun/99 \\
\hline 8 & 4,4 & - & 0,8 & 0,0 & 2,0 & - & - & Jun/99 \\
\hline 9 & 10,9 & - & 2,0 & - & - & - & - & Dez/98 \\
\hline 10 & 7,5 & - & 0,1 & 2,0 & - & - & - & Mar/99 \\
\hline 11 & 3,0 & - & 0,0 & 0,9 & - & - & - & Mar/99 \\
\hline 12 & 10,7 & - & 2,0 & 2,1 & - & - & - & Mar/99 \\
\hline 13 & 7,7 & - & 0,1 & 0,0 & - & - & - & Mar/99 \\
\hline 14 & 10,5 & - & 3,2 & 2,9 & - & - & - & Mar/99 \\
\hline 15 & 12,4 & - & 2,4 & 1,9 & - & - & - & Mar/99 \\
\hline 16 & 19,5 & - & 1,6 & 2,5 & - & - & - & Mar/99 \\
\hline 17 & 8,8 & - & 3,1 & 4,0 & 4,4 & - & - & Jun/99 \\
\hline 18 & 21,5 & - & 3,1 & - & - & - & - & Jun/99 \\
\hline 19 & 15,8 & - & 3,0 & 2,0 & 1,0 & - & - & Jun/99 \\
\hline 20 & 17,2 & - & 2,0 & 1,0 & - & - & - & Mar/99 \\
\hline 21 & 74,0 & - & 5,0 & - & - & - & & Dez/98 \\
\hline 22 & 69,0 & - & 3,0 & 2,0 & 2,4 & - & - & Jun/99 \\
\hline 23 & 14,0 & - & 6,9 & - & - & - & - & Dez/98 \\
\hline 24 & 18,6 & - & 0,1 & 0,3 & - & - & - & Mar/99 \\
\hline 25 & 3,5 & - & 2,0 & 2,1 & - & - & - & Mar/99 \\
\hline 26 & 3,1 & - & 0,9 & - & - & - & - & Dez/98 \\
\hline 27 & 10,7 & - & 2,1 & 2,0 & 1,8 & - & - & Jun/99 \\
\hline 28 & 0,6 & 3,7 & - & 0,1 & 0,3 & - & - & Jun/99 \\
\hline 29 & 0,9 & 6,8 & - & 1,0 & - & - & - & Mar/99 \\
\hline 30 & 1,0 & 4,2 & - & 2,3 & - & - & - & Mar/99 \\
\hline 31 & 0,1 & 8,9 & - & 3,2 & 0,0 & - & - & Jun/99 \\
\hline 32 & 1,3 & 22,6 & - & 4,8 & 0,1 & - & - & Jun/99 \\
\hline 33 & 1,1 & 21,0 & - & 3,3 & 0,9 & - & - & Jun/99 \\
\hline 34 & 1,6 & 5,9 & - & 0,6 & 0,9 & - & - & Jun/99 \\
\hline 35 & 2,0 & 13,3 & - & 4,9 & - & - & - & Mar/99 \\
\hline 36 & 0,2 & 3,0 & - & 0,3 & 1,1 & 0,3 & 1,9 & Dez/99 \\
\hline 37 & 1,0 & 2,8 & - & 1,2 & 1,3 & 1,8 & 1,7 & Dez/99 \\
\hline 38 & 0,9 & 3,6 & - & 1,4 & 1,0 & 2,0 & 2,1 & Dez/99 \\
\hline 39 & 0,6 & 2,4 & - & 0,6 & 0,0 & 0,4 & 0,9 & Dez/99 \\
\hline
\end{tabular}


O estudo bacteriológico teve início 90 dias após a última dose de isoniazida, em dezembro de 1998, com o abate de nove animais. Abates subseqüentes foram realizados em março, junho e dezembro de 1999. Foram semeadas 450 amostras de fragmentos de pulmões e fígado e de linfonodos. Dessas, foi possível isolar M. bovis a partir das lesões anatomopatológicas sugestivas de tuberculose nos pulmões, linfonodos mediastínicos e no fígado, somente de um animal, que entretanto não apresentava sinais clínicos da doença. Apesar de receber as 120 doses de isoniazida, esse animal apresentou à necropsia lesões de diâmetro variável. Esses aspectos foram relatados por Kleeberg (1967) e D’Ascani e Micozzi (1961), ao tratarem bovinos tuberculosos que apresentavam lesões semelhantes às encontradas neste animal. Segundo esses autores, bovinos com sintomas clínicos, provavelmente portadores de lesões, não devem ser submetidos ao tratamento da tuberculose com isoniazida pois as lesões não regridem com as dosagens e períodos de tratamento normalmente utilizados.

As duas amostras de M. bovis isoladas antes e após o tratamento e submetidas ao teste de resistência à isoniazida foram consideradas sensíveis a este medicamento. Este fato indicou que o tratamento da tuberculose pela isoniazida não resultou no aparecimento de cepas resistentes.

Kleeberg (1967) e Langenegger et al. (1981b) consideraram que a perda de virulência é válida para o M. bovis resistente à isoniazida. Isso significaria que ao tratar bovinos tuberculosos com isoniazida, os bacilos sensíveis morreriam e os resistentes seriam eliminados naturalmente, sem apresentar risco de infecção para outros bovinos. Esse fato precisa ser comprovado experimentalmente.

Após os primeiros quatro meses de medicação foi notado sensível melhora no estado geral dos animais e aumento considerável na produção de leite, diferente dos relatos de Kleeberg et al. (1961). Esses autores concluíram que o tratamento de vacas em lactação com isoniazida não tem influência direta na produção de leite.

Apesar dos resultados obtidos nesta pesquisa, principalmente quanto ao tratamento profilático com isoniazida, cuidados devem ser tomados quanto aos tratamentos indiscriminados.

O acompanhamento da dessensibilização alérgica por meio da tuberculinização comparada e o acompanhamento bacteriológico são métodos eficientes na avaliação da cura de animais infectados com $M$. bovis e submetidos ao tratamento com isoniazida.

\section{REFERÊNCIAS BIBLIOGRÁFICAS}

\begin{abstract}
AVELLINI, G.; FIGORELLI, L. Comportamento della reazione allergica tubercolínica in vitelli sperimentalmente infettati com micobatteri tubercolari i trattati com idrazide dellácido isonicotinico. Zooprofilassi, v.9, p.831-839, 1954.
\end{abstract}

CASTELLANI, G.; DESPOSITO, L; ZACCHI, B. Quimioprofilaxis de la tuberculosis. Nota 1. Actividad profilatica antituberculosa del idrozida isonicotinico en terneros nascidos y dejados en lugar infecto. CONGRESSO MUNDIAL DE VETERINÁRIA, 16., Madrid, 1959. P.699-700.

D'ASCANI, E.; MICOZZI, G. L' idrazide dell' acido isonicotinico sola od associata alla diidrostreptomicina nella chemioprofilassi della tubercolosi. Influenza esercitata da questi due medicamenti nei requardidela reazione tubercolinica. Zooprofilazzi, v.16, p.724, 1961.

KANTOR, I.N. Bacteriologia de la tuberculosis. Buenos Aires: Centro Panamericano de Zoonosis, 1998, 63p. Serie de Monografías Cientificas y Tecnicas, n. $^{\text {o }} 11 /$ Rev. I.

KLEEBERG, H.H. The use of chemotherapeutic agents in animal tuberculosis. Veterinarian, v.4, 197-211, 1967.

KLEEBERG, H.H.; GERICKE, J.J.; WEYLAND, H. The excretion and stability of isoniazid in cows milk. J. South Afr. Med. Assoc., v.32, p.482-486, 1961.

LANGENEGGER, J.; CAVALCANTE. M.I.; LIRA, A.D. Tratamento massal da tuberculose bovina com isoniazida. Pesq. Vet. Bras., v.11, p.21-23, 1991a.

LANGENEGGER, J.; LANGENEGGER, C.H.; MOTA, P.M.P.C. et al. Reações inespecíficas no diagnóstico alérgico d tuberculose bovina. Pesq. Vet. Bras., v.4, p.145-149, 1981a. 
LANGENEGGER, J.; LANGENEGGER, C.H.; OLIVEIRA J. Tratamento da tuberculose bovina com isoniazida. Pesq. Vet. Bras., v.1, p.1-6, 1981b.

LANGENEGGER, J.; LANGENEGGER, C.H.; RAMOS, A.A. Reações alérgicas inespecíficas no diagnóstico da tuberculose em bovinos causadas por Mycobacterium intracellulare. Pesq. Vet. Bras. Ser. Vet., v.11, p.65-71, 1976.

LANGENEGGER, J.; LEITE, O.G; OLIVEIRA, S. Tratamento intermitente da tuberculose bovina com isoniazida. Pesq. Vet. Bras., v.11, p.55-59, 1991b.

MORETTI, B.; PEDINI, B. Primi rilliev sul trattament, com idrazide dell acido isonicotinico, de forme acute di tuberculosi bovina. Nuova Vet., v.28, p.345-351, 1952.

MORETTI, B.; PEDINI, B. Sulla attivistá preventiva antitubercolare nel vitello nell'idrazide dellácio isonitimico. Nuova Vet., v.29, p.322-324, 1953.

MOTA, P.M.P.C. Estudo da esofagostomose como fator predisponente de reações alérgicas inespecificas da tuberculose bovina. 1985. 70p. Tese (Mestrado) - Escola de Veterinária, Universidade Federal de Minas Gerais, Belo Horizonte.

SEELEMANN, M.; BUSCHKIEL, H. Chemoprophulaktische versuche bei Rindertuberkulose. II. Versuche inter praktische verhaltnissen in tuberkulose verse uchten Herden. 2bl. Vet. Med., v.4, p.101-118,1957.

SHINNICK, T. M. Tuberculosis. Current topies in microbiology and immunology. Atlanta: T. M. Shinnick, 1996. 307p.

SPRYSZAK, A. Control of bovine tuberculosis with reference to chemoprofhlaxis in calves. Bull. Int. Epiz., v. 56, p. 954-958, 1961. 